\title{
19.
}

\section{Escenas de Cambuci}

\section{Vivian Castro}

\section{Resumen:}

Este ensayo fotográfico es parte de un proyecto personal en curso sobre el barrio de Cambuci, São Paulo. Conocido por ser un barrio histórico de la ciudad, presento un relato libre a partir de mi propia experiencia como moradora. Escenas cotidianas son observadas y registradas con anotaciones textuales y fotografías realizadas con una cámara análoga.

Palabras-clave: Fotografía, Documental, Cambuci, Cotidiano.

\section{Resumo:}

Este ensaio fotográfico é parte de um projeto pessoal em curso sobre o bairro de Cambuci, São Paulo. Conhecido por ser um bairro histórico da cidade, presento uma narrativa livre a partir da minha própria experiência como moradora. Cenas cotidianas são observadas e registradas por meio de anotações textuais e fotografias realizadas com uma câmera análoga.

Palavras-chave: Fotografia, Documental, Cambuci, Cotidiano.

\begin{abstract}
:
This photo essay is part of a personal project which is still in progress about the neighborhood of Cambuci, São Paulo. Known for being a historical part of the city, I have presented free narratives from my own experience as a resident. Everyday scenes are observed and recorded with textual annotations and photographs taken with an analog camera.
\end{abstract}

Keywords: Photography, Documentary, Cambuci, Daily. 


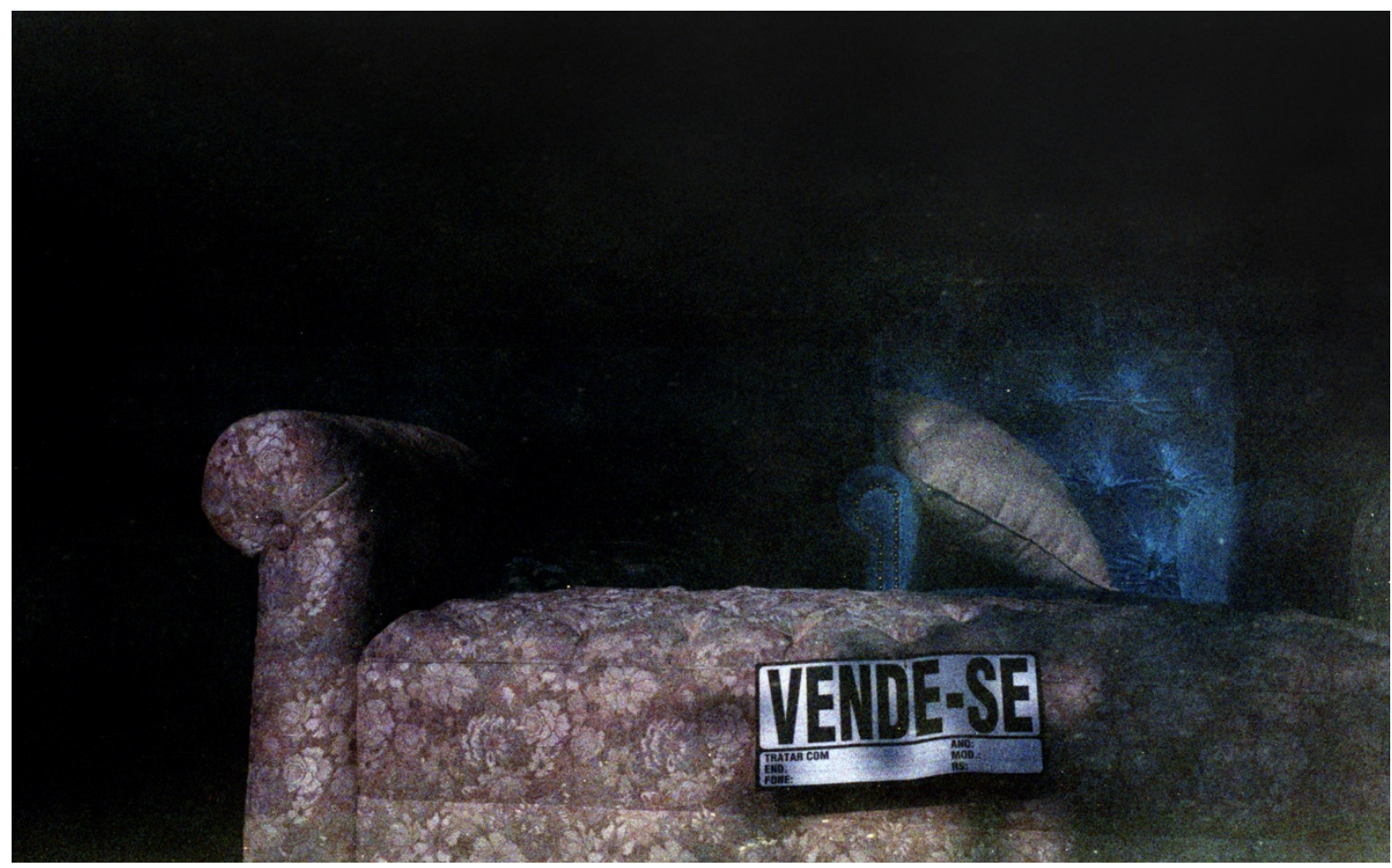

Vivian Castro, Escenas de Cambuci 1, 2018.

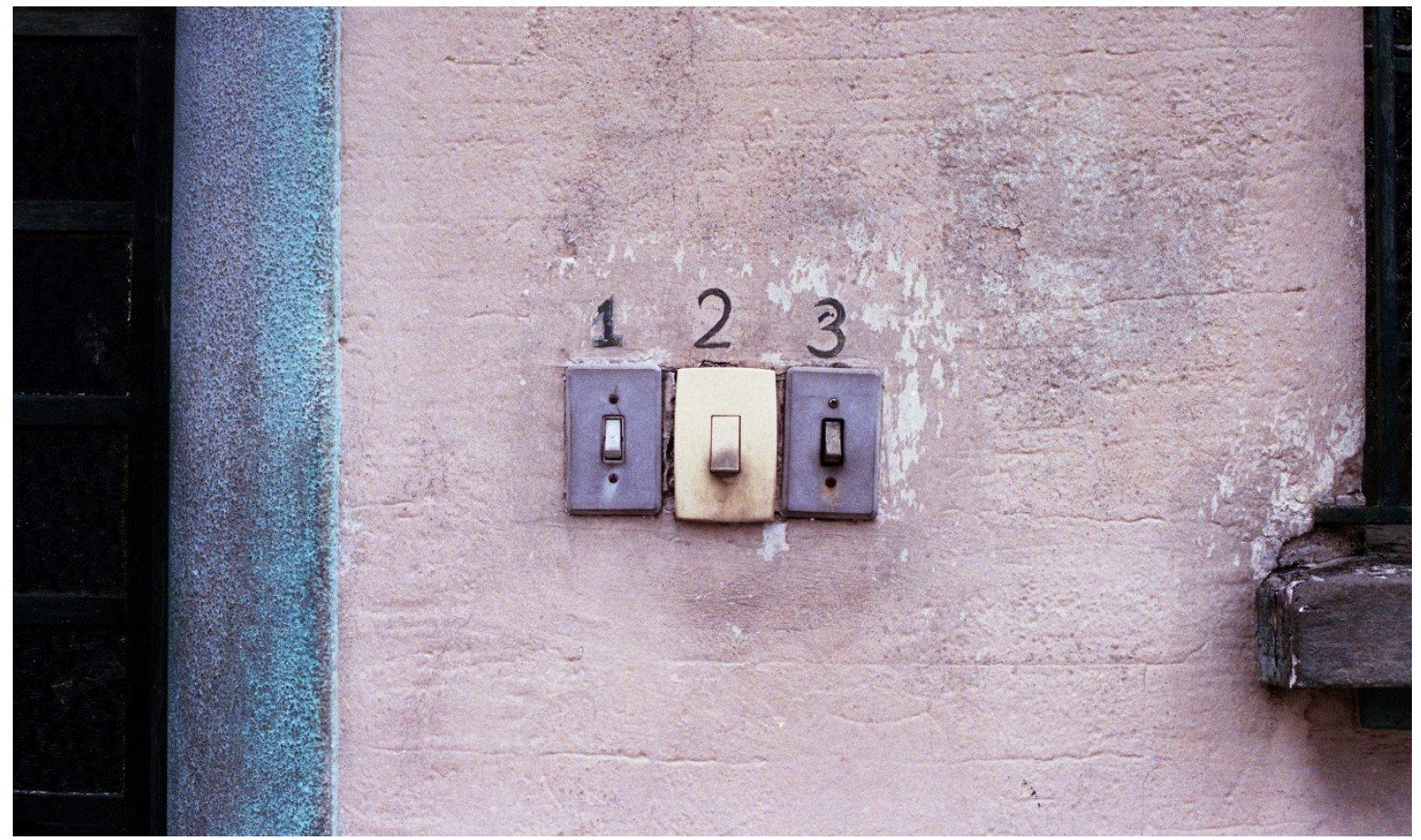

Vivian Castro, Escenas de Cambuci 2, 2018. 


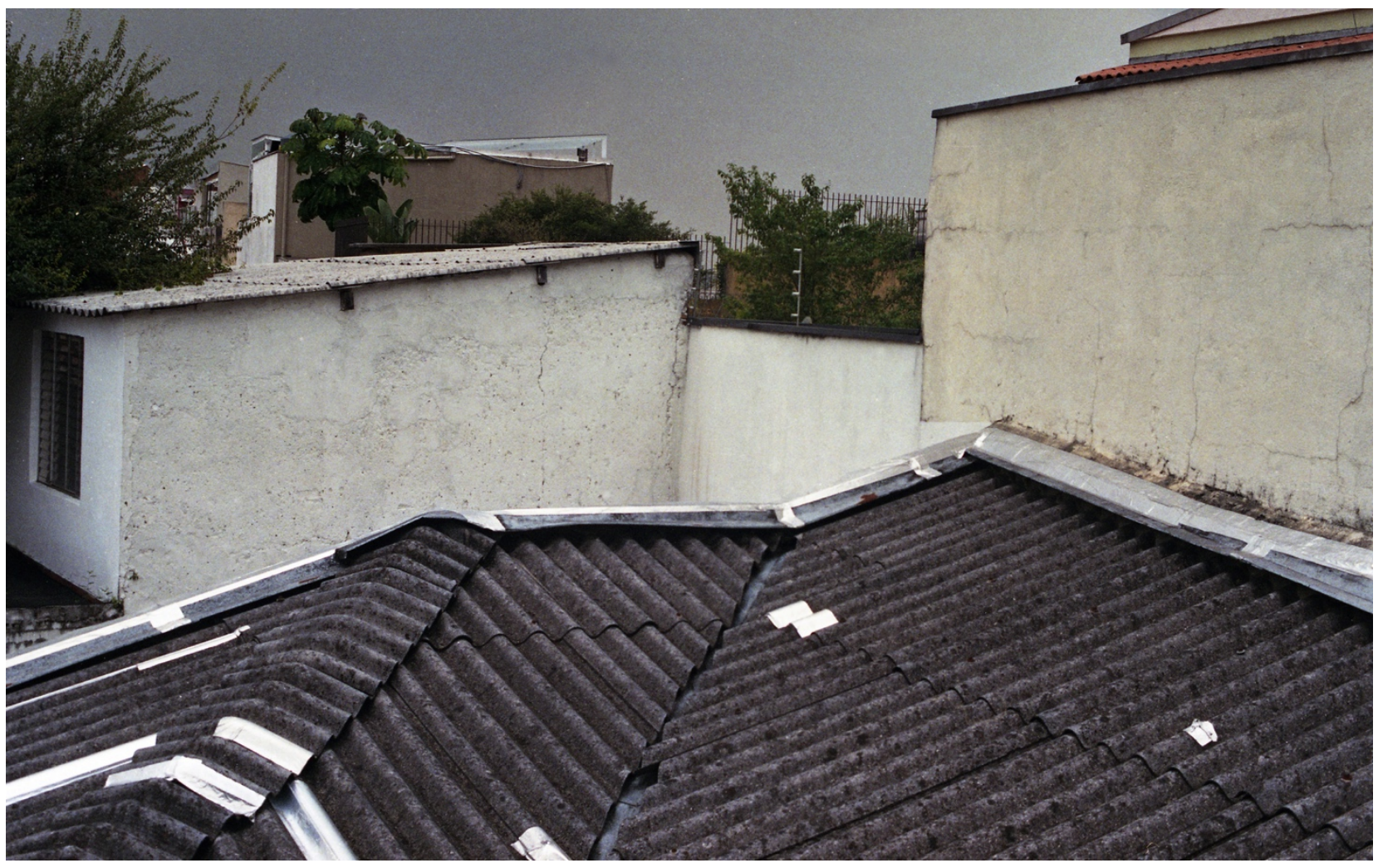

Vivian Castro, Escenas de Cambuci 3, 2018.

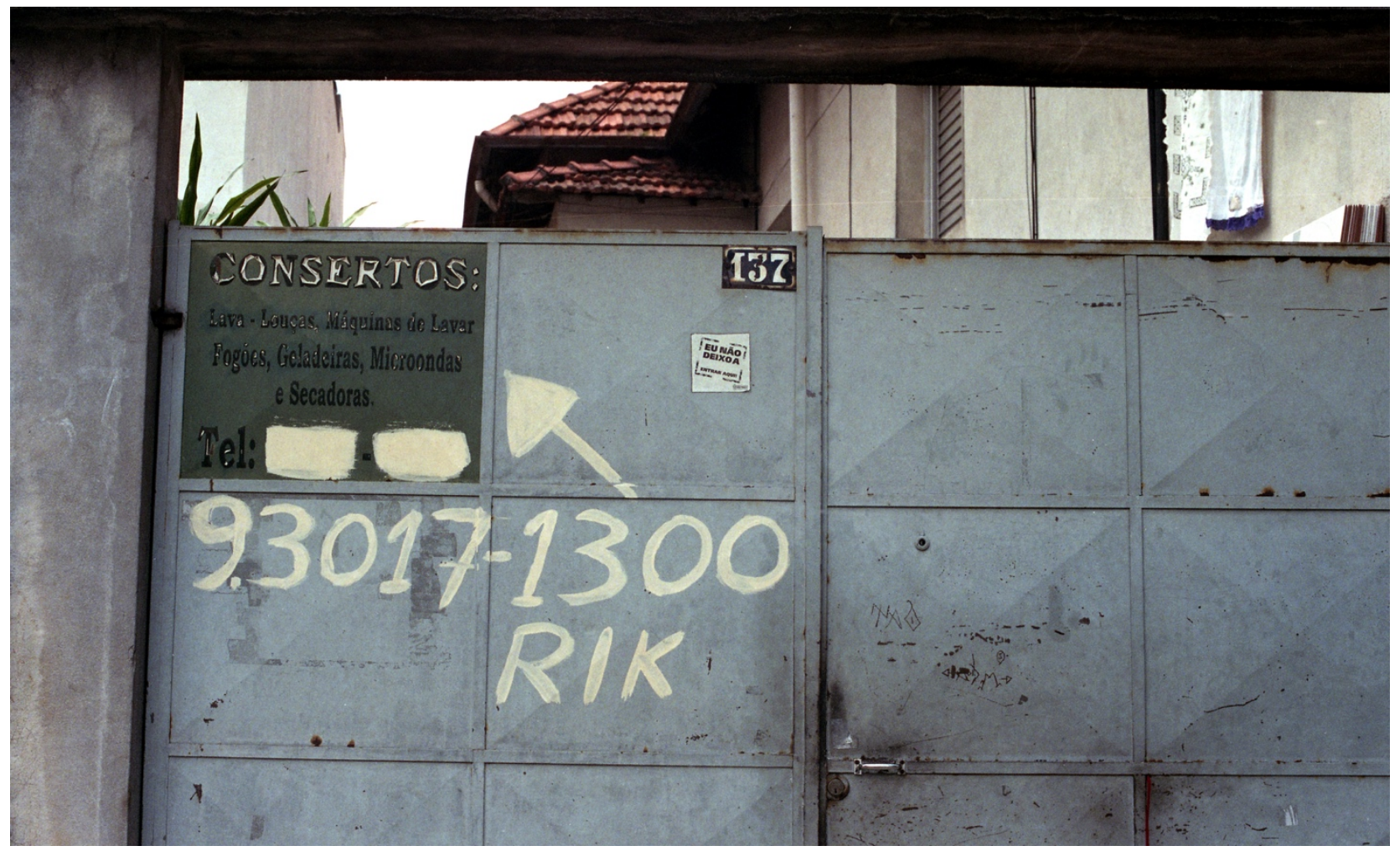

Vivian Castro, Escenas de Cambuci 4, 2018. 


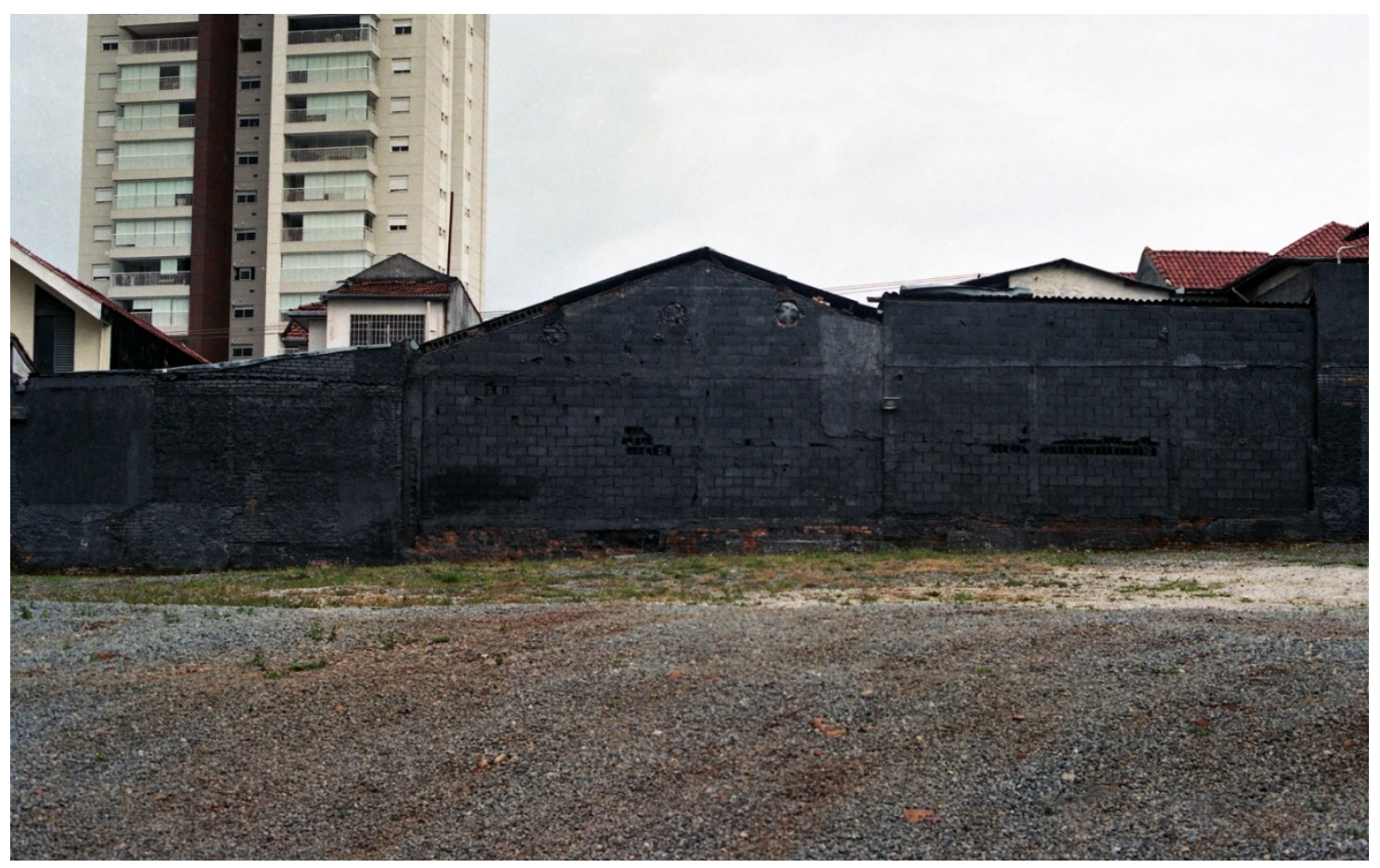

Vivian Castro, Escenas de Cambuci 5, 2018.

"É a cara do Cambuci", me dijo, cuando vimos un viejo Volkswagen quemado, a plena luz del día, camino a almorzar. Pena no tener una cámara, pensé enseguida, pero ya había decidido que haría el trabajo apenas con película. No era solamente un fetiche personal, sino que la materialidad de la película remite, así como el barrio, al siglo pasado: 1910,1913 es posible leer en algunas fachadas de las casas.

Escribo antes de revelar el primer rollo. Tal vez eso sea algo bueno de trabajar con película, calma la ansiedad de la buena foto. En general, en un ensayo fotográfico el texto viene después, para complementar aquello que se encuentra en las imágenes. Por el contrario, estoy imaginando las fotografías antes de registrarlas. Imaginándolas a partir de lo que ya vi, de lo que veo siempre. De hecho, hay varias que tengo pensadas y otras que me perdí el "instante decisivo", popularizado por el fotógrafo Henri CartierBresson, y solo puedo describirlas. Hoy, por ejemplo, varias escenas cotidianas en la Rua do Lavapes, entrando al barrio Cambuci. "Aqui é onde os tropeiros lavavam seus pés, no Córrego do Lavapés" le dijo, a un distraído motorista de Uber. Tal vez no llegue a fotografiar hasta allá, en realidad me gusta ese registro visual fugaz, en movimiento. Un paisaje hecho solo de palabras escritas: Eleições gerais já!; Sou brasil; Aluga se quarto; Paraíso das essencias; Las Vegas; Vândalo da mamãe; Hello! Welcame; Não contra o aumento; Nasci para vencer; Funilaria; Te amo pai; Mania brasileira; Oficina dois amigos; Olhai por nois; Haiti; Mais amor por favor. 


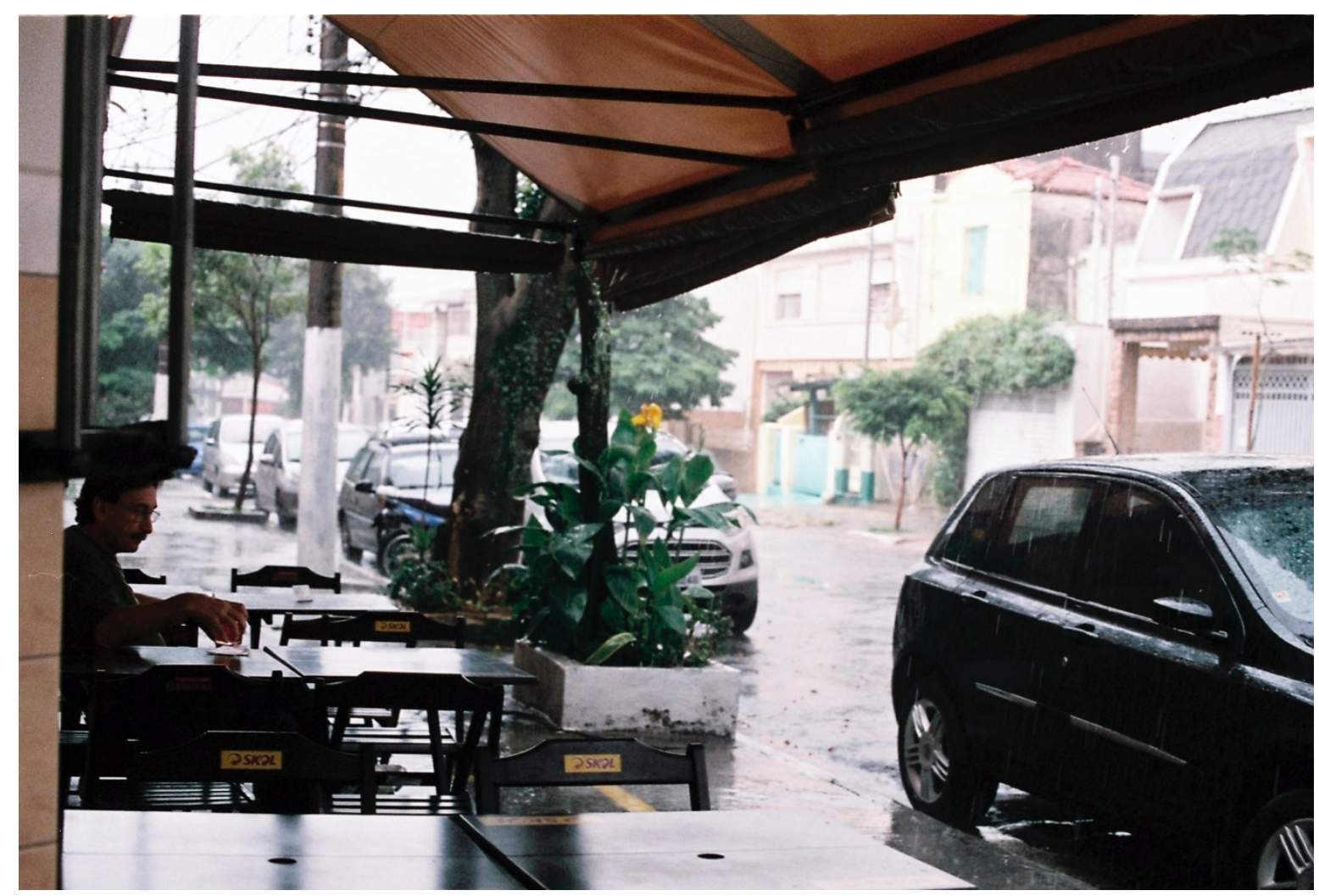

Vivian Castro, Escenas de Cambuci 6, 2018.

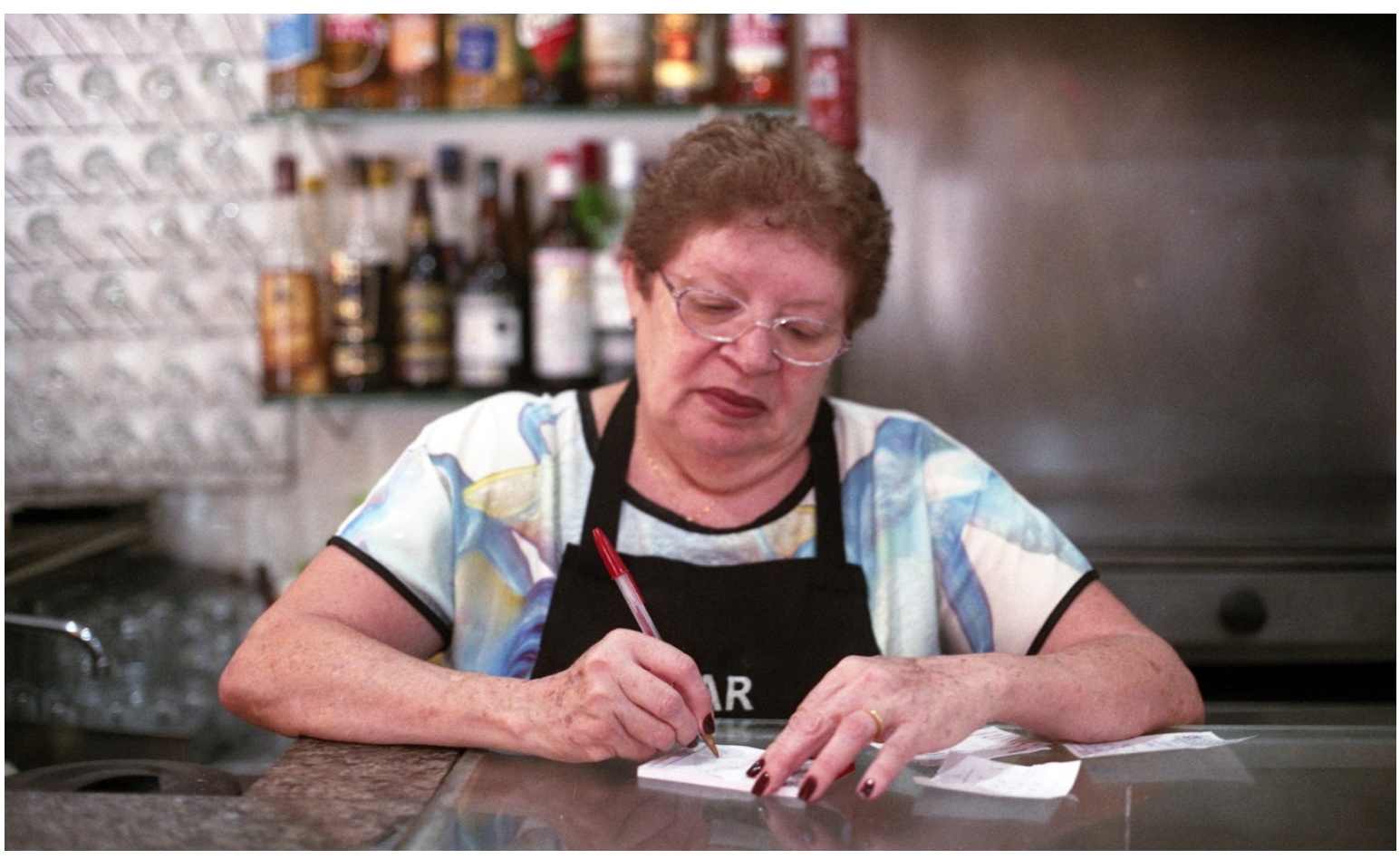

Vivian Castro, Escenas de Cambuci 7, 2018. 


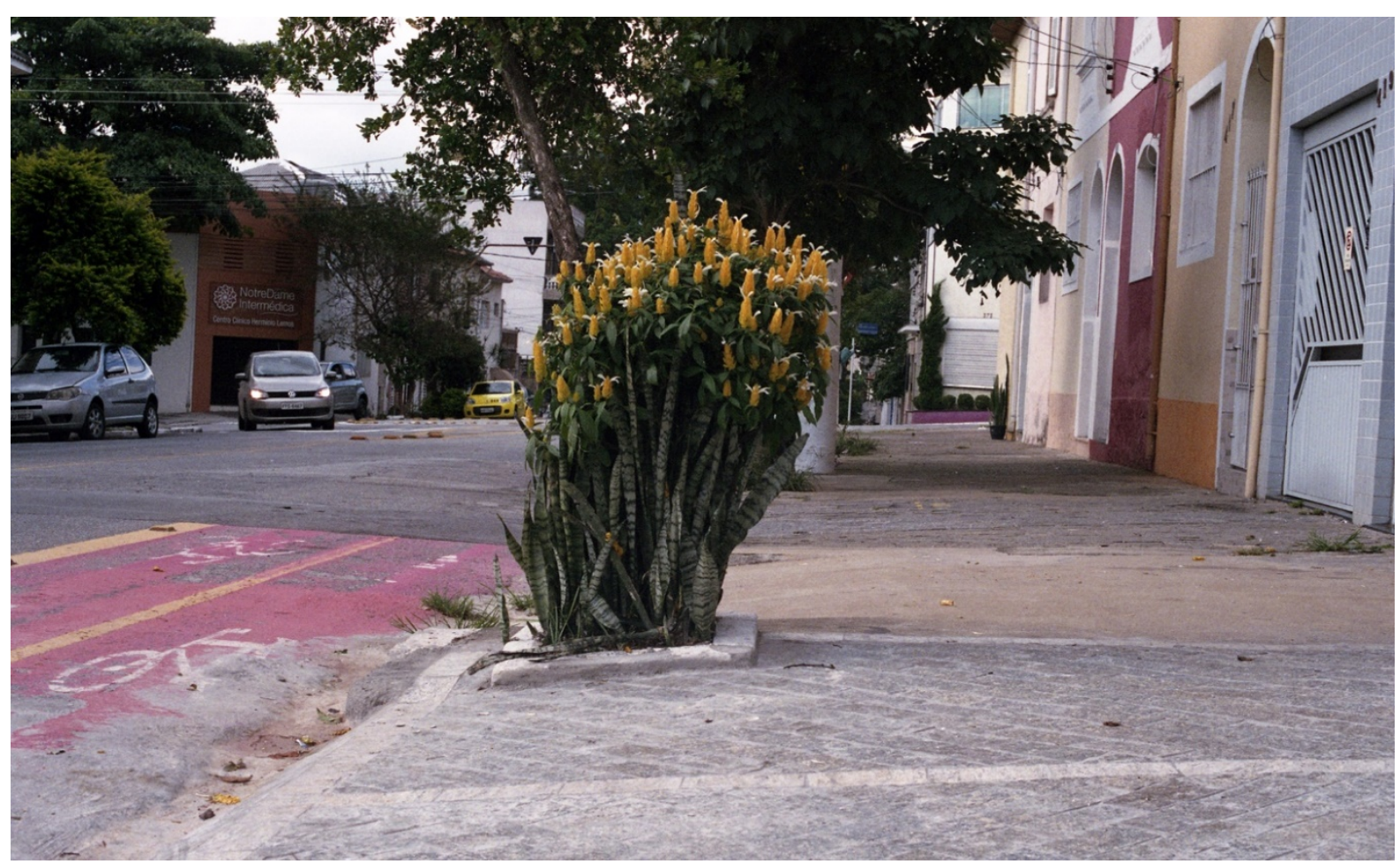

Vivian Castro, Escenas de Cambuci 8, 2018.

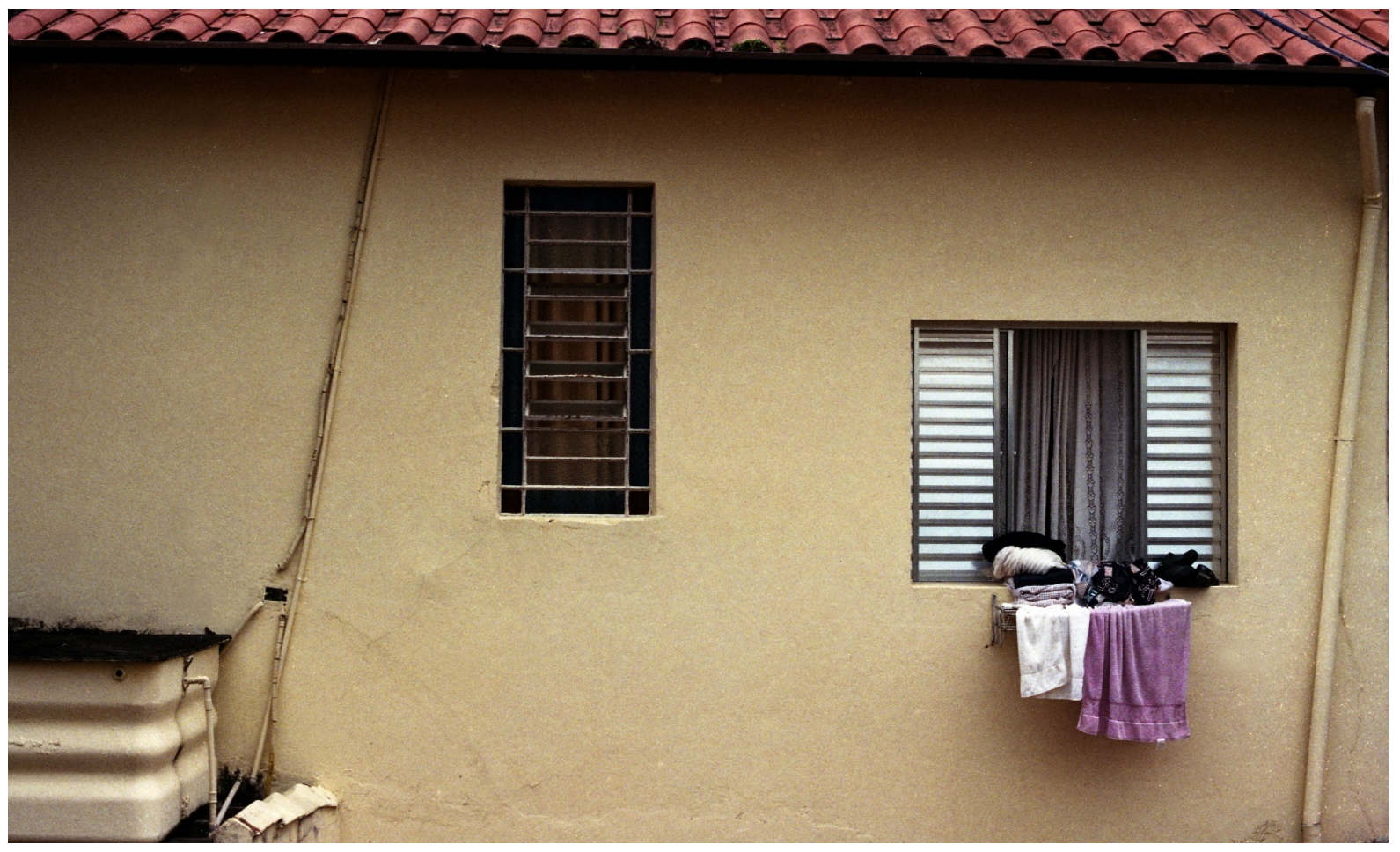

Vivian Castro, Escenas de Cambuci 9, 2018. 


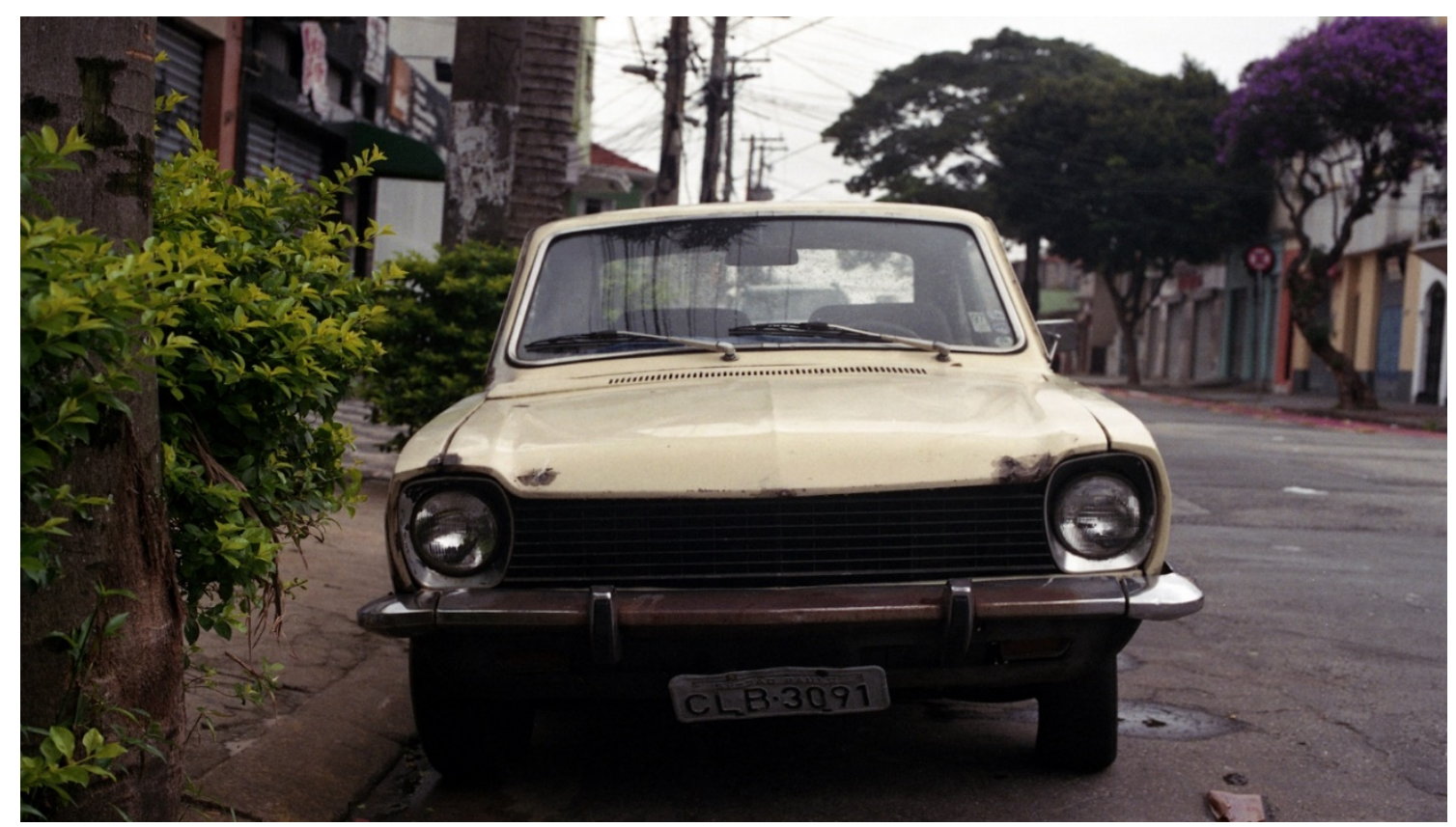

Vivian Castro, Escenas de Cambuci 10, 2018.

Primero cerro el bar de la esquina, por segunda vez, en menos de tres años. Luego una y otra casa vecina que se vende. Solo en una manzana del barrio, por lo menos unas 10 casas. De pronto, la especulación inmobiliaria llega cerca. Contamos: uno, dos, tres terrenos baldíos a la espera de construcción de edificios. Fantaseamos plazas con juegos para niños. Lo bueno es que, con la crisis, hay un terreno que lleva más de 2 años sin poder conseguir comenzar a construir. Curiosamente se llama "Wondeful Aclimação".

De pronto la casa blanca que desentona. Nueva: sin manchas, sin historia, sin recuerdos. 1.250.000 mil reales dicen que vale, nunca van a venderla, dicen otros. Por lo menos es una casa, pienso yo. Pareada al lado derecho, otra casa que parece un hogar de ancianos. Cuando sale el sol, en silla de ruedas, un viejito observa la calle. Él y la casa blanca forman un contraste de lo viejo y lo nuevo, tan común en las fotografías de comienzos del siglo $\mathrm{XX}$, transmitiendo la idea que la ciudad precisaba transformarse para ser moderna.

Cambuci mantiene todavía ciertas dinámicas de barrio. Vecinos que se saludan de lejos, gente haciendo asados, personas ocupando la calle. Otros paseando perros. El bar a la vuelta de la esquina, pedir lo mismo de siempre: martes bife a parmegiana, miércoles carne con berenjena, jueves tallarines con salsa, viernes bacalao, y así se van los días. Mirar las tardes los bares llenos de un grupo de señores de avanzada edad que de a poco conversan a los gritos junto a las botellas que se acumulan en las mesas. La ropa 
tendida, Dona Jura en la puerta, los techos torcidos de Alfredo Volpi.

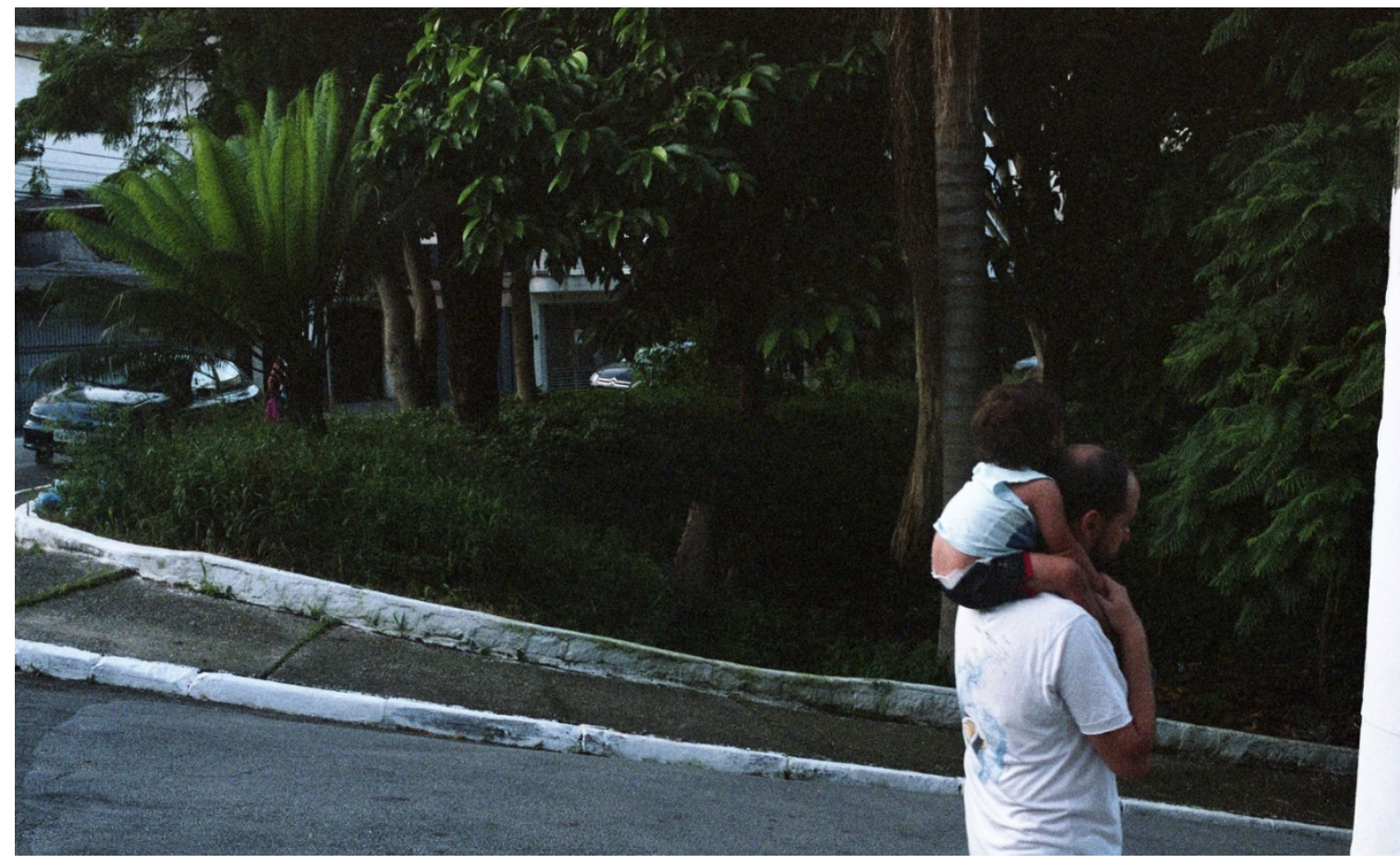

Vivian Castro, Escenas de Cambuci 11, 2018.

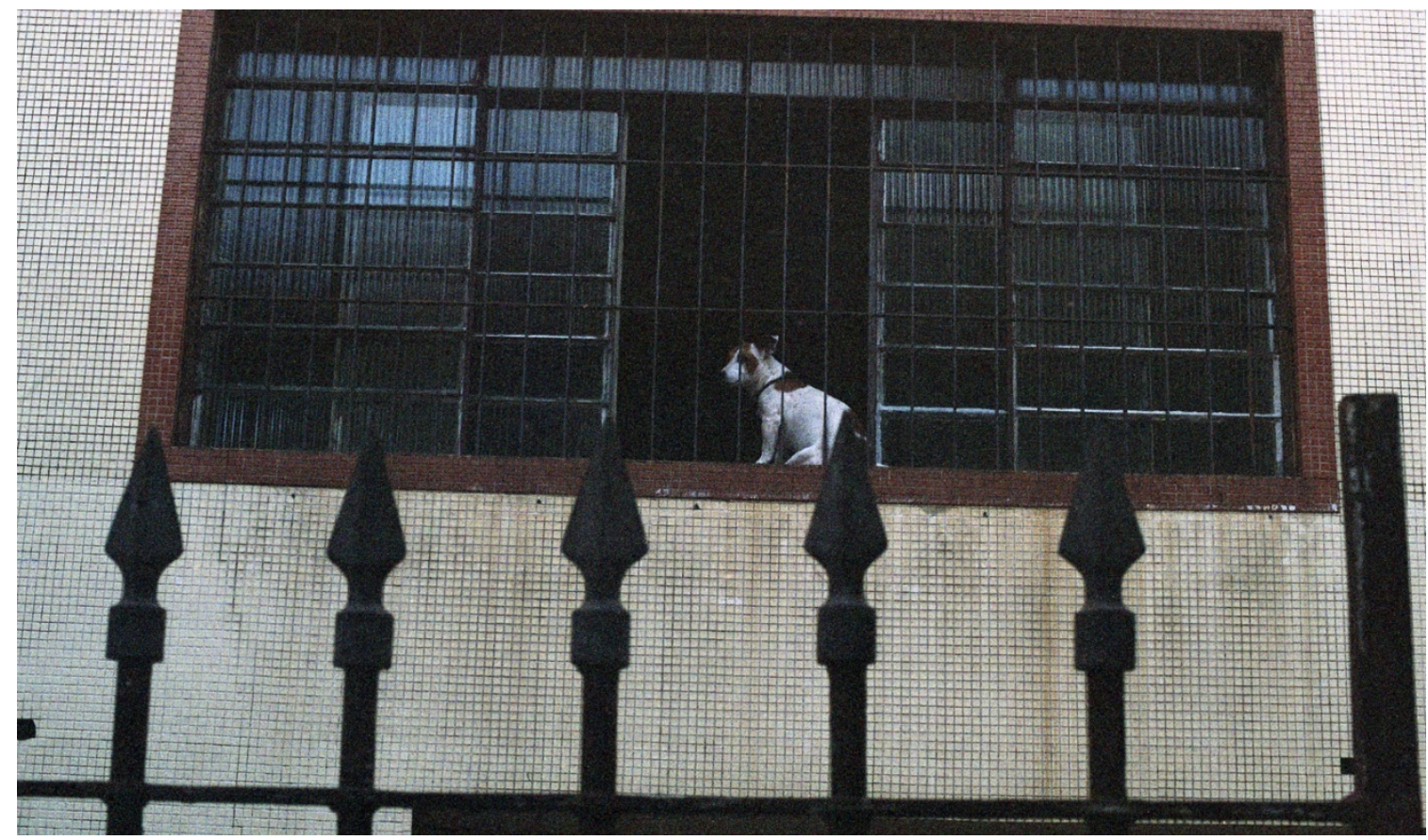

Vivian Castro, Escenas de Cambuci 12, 2018. 


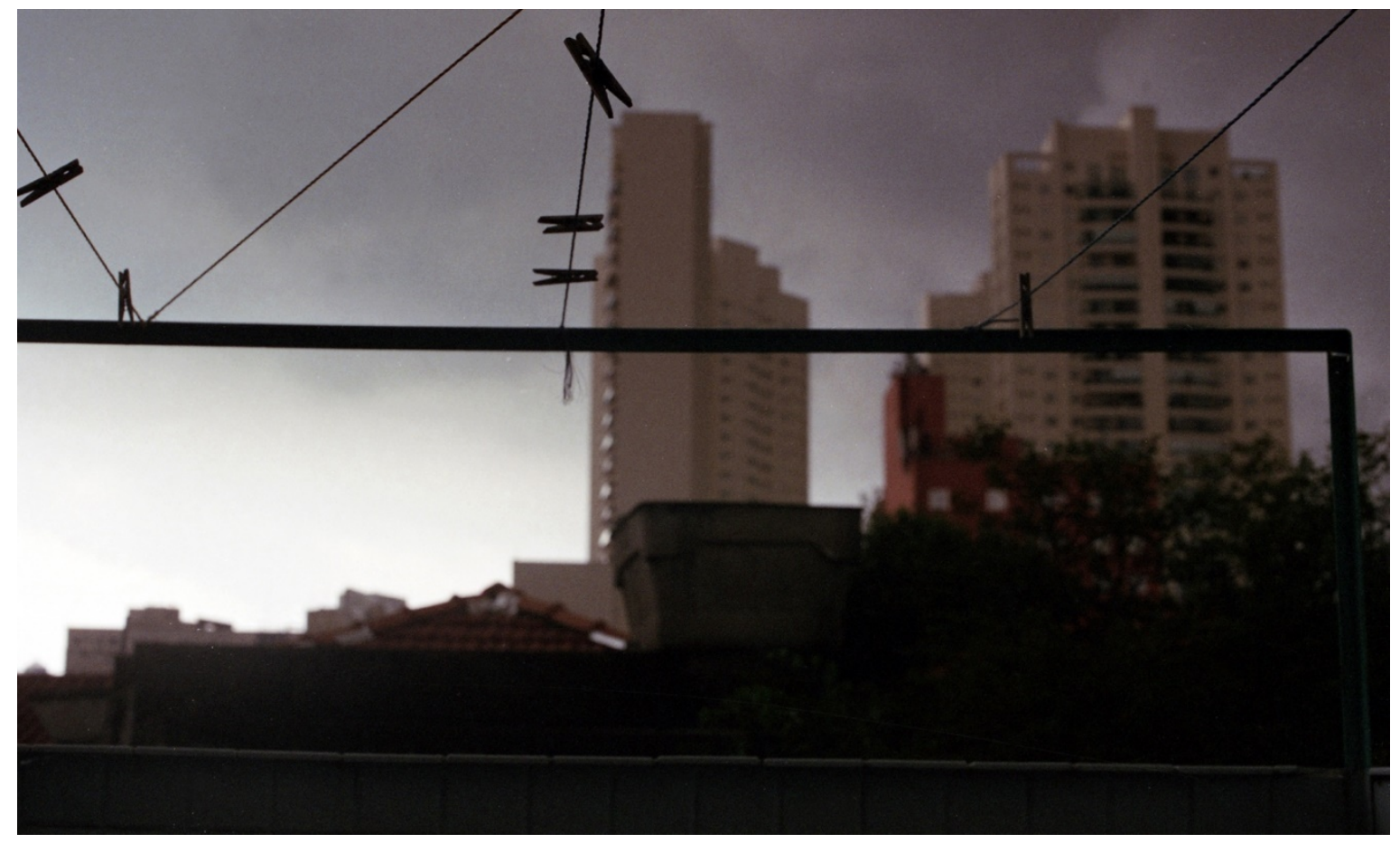

Vivian Castro, Escenas de Cambuci 13, 2018.

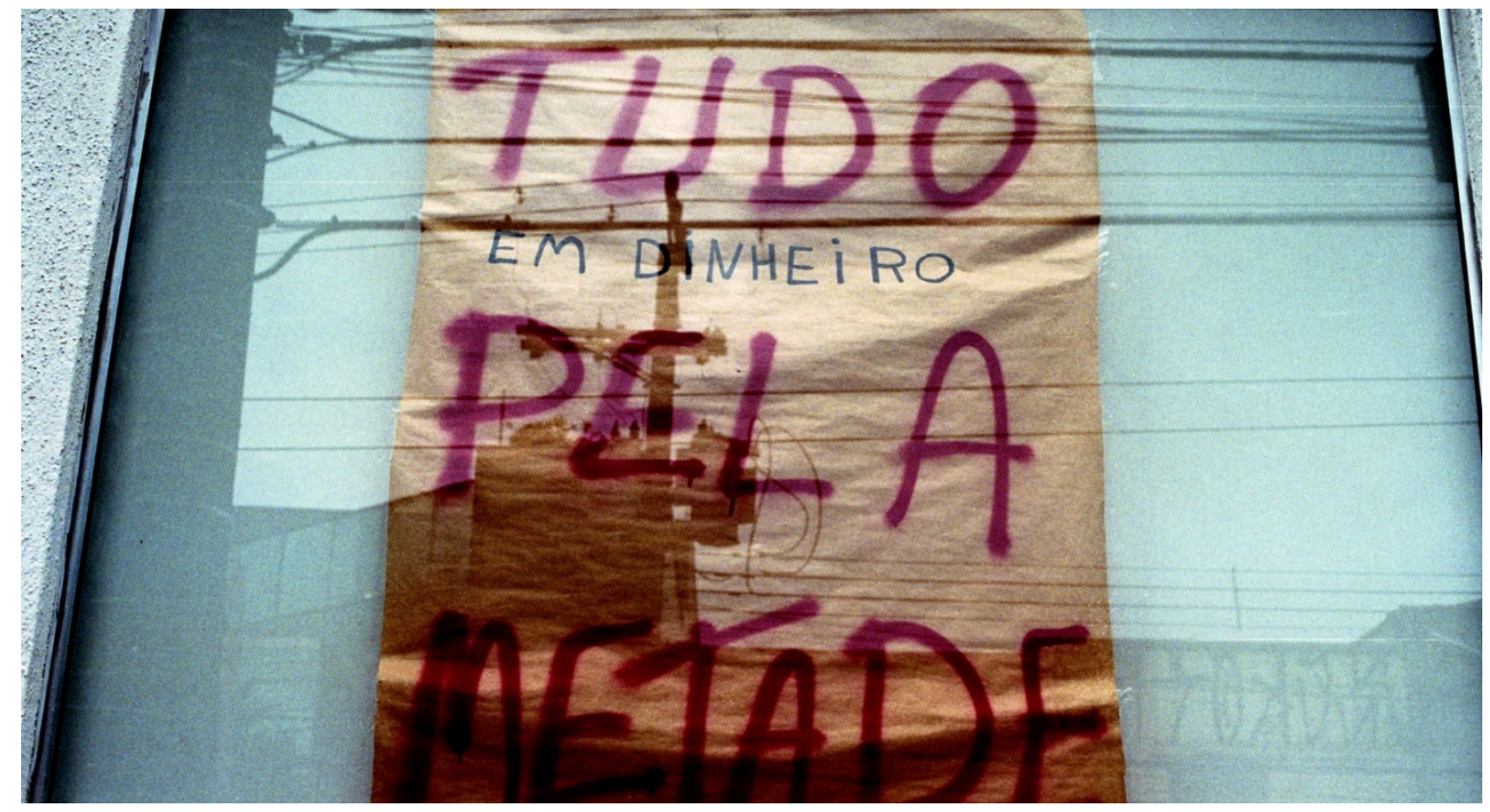

Vivian Castro, Escenas de Cambuci 14, 2018. 


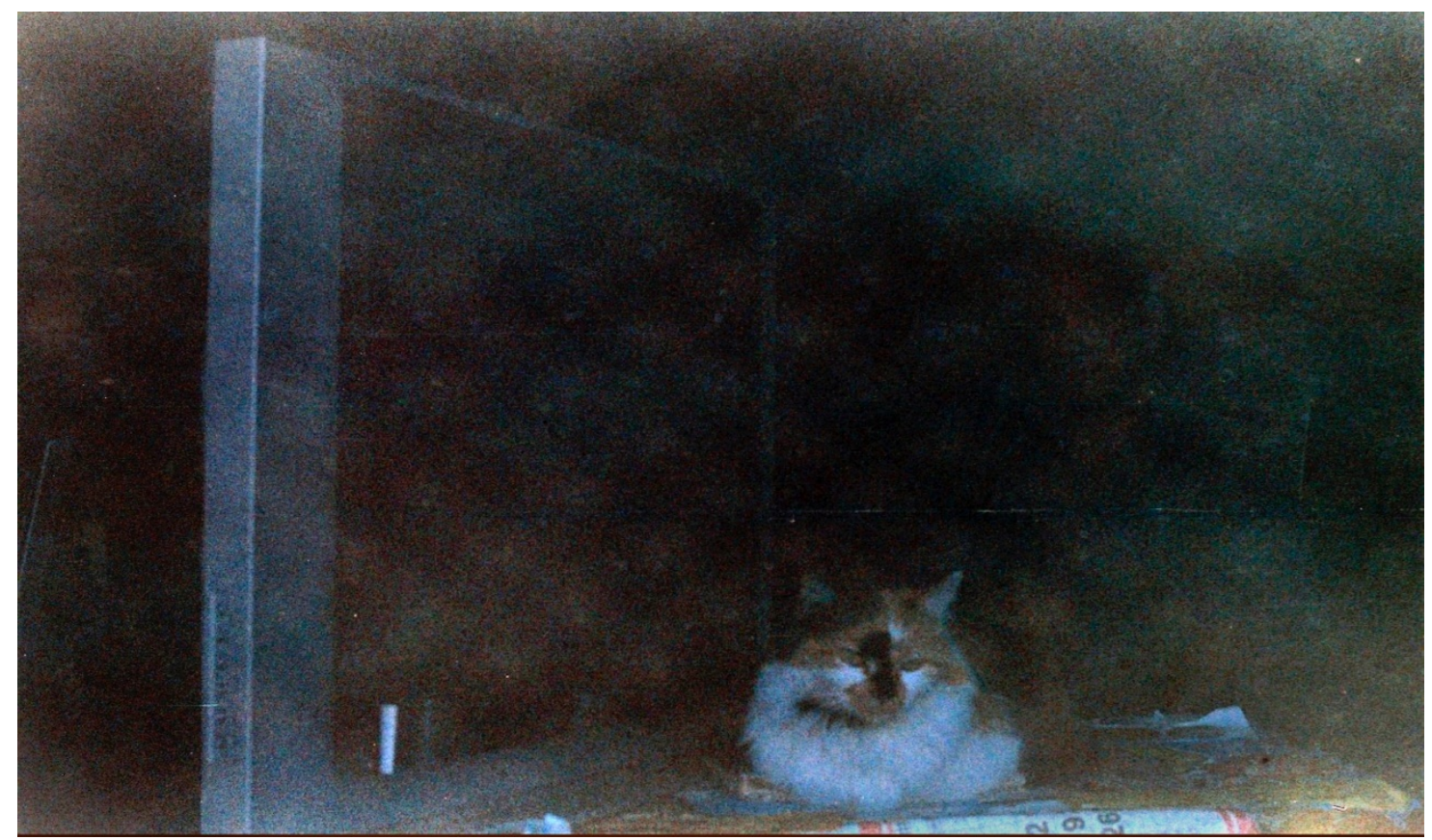

Vivian Castro, Escenas de Cambuci 15, 2018.

¿Quien manda a arreglar una televisión en estos días? Me gustan las tiendas donde se arreglan cosas, el barrio tiene varias y variadas: zapatos, televisores, ropa, autos, muebles, computadores. Nada nuevo, todo usado.

"Estou por retirarme já" me dice Abenaldo, debo haber hecho su retrato imaginariamente por lo menos unas 5 veces. Cada vez que pase por el frente de su tienda. Un día me animé y le comenté que hacía un reportaje fotográfico sobre el barrio. No pareció muy convencido. Le comenté que me interesaba la cotidianeidad del barrio que está por desaparecer, y mencioné la cantidad de casas a la venta y edificios en construcción. Ahí logre su atención. El día que fui a visitarlo hice de improviso la fotografía, quería capturar exactamente el rostro que tenía en mi mente: una suerte de melancolía y pasividad. Esa sensación también me da el barrio, por lo menos ahora, no sé si por la cantidad de viejitos que aquí viven, por la antigüedad que muestran sus fachadas, por el silencio nocturno, o porque soy yo la melancólica.

Del retrato de Abenaldo sobro sólo su gato que conseguí rescatar luego de que mi cámara se rompiera. El gato junto a uno de los varios televisores que componían la escena y la silueta perdida de Abenaldo en el fondo. Perdí también varios recorridos por el barrio: la notaria, la peluquería, el señor que arregla zapatos, el que arregla muebles, mis vecinos cercanos. Pienso que esa es una dimensión que me interesa para el trabajo: un retrato del barrio donde conviven lo público y lo privado.

Memorizo las escenas que veo en la calle, de pronto todo me parece interesante para fotografiar. La lluvia de la tarde, mensajes anónimos dejados en la puerta, el gris azulado 
del cielo, los arreglos del pavimento en año de elecciones, la viejita que da comida a las palomas todos los días a la misma hora, una sombra, una pequeña luz, un aire decadente, mi propia mirada que lo busca. Tal vez debería hacer otros recorridos. Quedarme quieta, esperar. Aunque me interesa este tiempo cotidiano en que "nada está sucediendo". Fotografía de los tiempos banales, dice André Rouillé.

Una última imagen: hombres sentados en la vereda a la hora de almuerzo, descansando, en el suelo. Es una imagen que me gusta, de la ciudad que no para.

\section{Referências bibliográficas}

Cartier-Bresson, H. (1971) O instante decisivo, in Bacellar (org.). Fotografia e Jornalismo (pp.19-26). São Paulo: Editora USP, ECA.

Rouillé, A. (2009). A fotografía: entre documento e arte contemporânea. São Paulo: SENAC.

Vivian Castro, artista visual chilena, vive e trabalha em São Paulo desde 2014. Possui graduação em Artes Visuais, com especialidade em Fotografia, pela Universidad de Chile (2007). É mestre (2016) e doutoranda em Meios e Processos Audiovisuais pela Universidade de São Paulo. Seu trabalho tem sido exposto em diversos museus, centros culturais e espaço público do Chile, Uruguai e Brasil. Em Montevidéu, foi professora de Fotografia na Universidad Católica del Uruguay e na Universidad de la República. 